\title{
No effects of increased alcohol availability during adolescence on alcohol-related morbidity and mortality during four decades: a natural experiment
}

\author{
Emelie Thern, ${ }^{1}$ Ting Jia, ${ }^{1}$ Mikaela Willmer, ${ }^{1,2}$ Jeroen de Munter, ${ }^{1}$ Thor Norström, ${ }^{3}$ \\ Mats Ramstedt, ${ }^{4}$ George Davey Smith, ${ }^{5,6}$ Per Tynelius, ${ }^{1,7}$ Finn Rasmussen ${ }^{1,7}$
}

\begin{abstract}
- Additional material is published online only. To view please visit the journal online (http://dx.doi.org/10.1136/ jech-2017-209164).

'Department of Public Health Sciences, Karolinska Institutet, Stockholm, Sweden ${ }^{2}$ Department of Health and Caring Sciences, Faculty of Health and Occupational Studies, University of Gävle, Gävle, Sweden

${ }^{3}$ Swedish Institute for Social Research, Stockholm University, Stockholm, Sweden

${ }^{4}$ The Swedish Council for Information on Alcohol and Other Drugs, Stockholm, Sweden

${ }^{5} \mathrm{MRC}$ Integrative Epidemiology Unit (IEU), University of Bristol, Bristol, UK

${ }^{6}$ Population Health Sciences, Bristol Medical School University of Bristol, Bristol, UK ${ }^{7}$ Centre for Epidemiology and Community Medicine, Stockholm County Council Health Care Services, Stockholm, Sweden
\end{abstract}

\section{Correspondence to} Emelie Thern, Department of Public Health Sciences, Karolinska Institutet, Stockholm 171 77, Sweden; emelie.thern@ ki.se

Received 7 March 2017 Revised 17 August 2017 Accepted 1 September 2017 Published Online First 18 September 2017

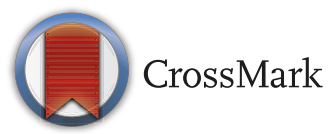

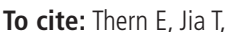
Willmer $\mathrm{M}$, et al. J Epidemiol Community Health 2017:71:1072-1077.

\section{ABSTRACT \\ Background A strict high legal age limit for alcohol purchases decreases adolescents' access to alcohol, but little is known about long-term health effects. The aim was to estimate the effect of increased alcohol availability during adolescence on alcohol-related morbidity and mortality.}

Methods A nationwide register-based study using data from a natural experiment setting. In two regions of Sweden, strong beer (4.5\%-5.6\% alcohol by volume) became temporarily available for purchase in grocery stores for individuals 16 years or older (instead of 21) in $1967 / 1968$. The intervention group was defined as all individuals living in the intervention area when they were $14-20$ years old $(n=72110)$. The remaining Swedish counties excluding bordering counties, without the policy change, were used as the control group ( $n=456224)$.

The outcomes of alcohol-related morbidity and mortality were collected from the Hospital Discharge Register and Cause of Death Register, in which average follow-up times were 38 years and 41 years, respectively. HRs with 95\% Cls were obtained by Cox regression analysis.

Results In the fully adjusted model, no clear evidence of an association between increased alcohol availability during adolescence and alcohol-related morbidity (HR:

$0.99,95 \% \mathrm{Cl} 0.96$ to 1.02 ) or mortality (HR: 1.02 , $95 \% \mathrm{Cl} 0.95$ to 1.10 ) was found.

Conclusion The initial elevated risk of alcohol-related morbidity and mortality later in life among adolescents exposed to increased access to strong beer in Sweden vanished when a regional measure population density of locality was included in the model, which is important to consider in future research.

\section{INTRODUCTION}

Alcohol is a top policy and public health issue as it is one of the leading causes of ill-health and premature death. ${ }^{1}$ Alcohol research benefits from using natural experiments method since it is difficult and unethical to manipulate alcohol exposure experimentally. $^{2}{ }^{3}$ Decreasing alcohol availability to adolescents by enforcing a high legal age limit for alcohol purchases has demonstrated beneficial short-term effects when it comes to curbing adolescent drinking and acute alcohol-related harm (ie, drunk driving and injuries). ${ }^{4}$ However, only a few studies have investigated the long-term effects of decreasing the legal age limit, ${ }^{6-9}$ research that is important in order to better understand the public health consequences of adolescent drinking. ${ }^{10-12}$
A vast amount of research on the long-term effects of changing the legal age for purchasing alcohol stems from the USA. Between the 1970s and 1980s, several states lowered the age limit for purchasing alcohol from 21 to 18 years, which was later increased back to 21 in all states. ${ }^{5}$ Research suggests that adolescents exposed to a lower age limit (18 years) instead of 21 years were at a higher risk of binge drinking during adulthood, alcohol or drug use disorder and alcohol-related mortality. ${ }^{6-8}$ These results support the notion that enforcing a higher legal age limit could be beneficial in the long term, which is important to further investigate in a context with a different alcohol policy and where the policy change affects an even younger age group. ${ }^{13} 14$

Sweden has a strict alcohol policy, with its retail monopoly restricting alcohol availability through, for example, high legal age limits. ${ }^{15}$ There are, however, a few instances when the alcohol policy has been relaxed in relation to lowering the legal age limit. Two such instances are during the 1960s; first medium-strength beer became nationally available in grocery stores in 1965 with an age limit of 16 years instead of 21 years and 2 years later strong beer was also made temporally available in grocery stores in two regions of Sweden with the same age limit. ${ }^{16} 17$ Research from Sweden found that adolescents exposed to a more lenient alcohol policy reported a slightly higher alcohol consumption in adulthood compared with adolescents exposed to a stricter alcohol policy. ${ }^{18}$ Furthermore, two studies using the same policy experiment as in the current paper, that is, the strong beer experiment, have been published. Results of the first study suggests a positive association between exposure to increased alcohol availability during adolescence and receiving disability pension due to all-cause, alcohol abuse and mental disorders later in life. ${ }^{9}$ Results of the second study suggest that children of younger mothers (below 21 years) exposed to the alcohol policy change in utero had worse economic outcomes at age 30 years. ${ }^{19}$

Policy changes could potentially have differential effects on socioeconomic groups. Previous research has found that individuals with low socioeconomic status (SES) are more vulnerable to the harmful effects of alcohol compared with individuals with high SES. ${ }^{2021}$ Furthermore, decreasing alcohol taxes appears to disproportionately impact the drinkers of low $\mathrm{SES}^{22} 23$; however, little is known 
about socioeconomic differences in response to a decrease in legal age limit for alcohol purchases.

The main aim of the present paper is to shed light on longterm effects of decreasing the legal age limit for purchasing alcohol on alcohol-related morbidity and mortality. For this investigation, we will be using data from the natural experiment in Sweden during the late 1960s when strong beer was available for purchase for individuals aged 16 years or older during a limited time period in a geographically delimited area.

\section{METHODS}

\section{Setting}

Between 1 November 1967 and 14 July 1968, an alcohol policy experiment took place in Gothenburg and Bohus County and Värmland County (referred to as the intervention area below). Within this area and time period, strong beer, containing 4.5\%$5.6 \%$ alcohol by volume, became available in regular grocery stores for individuals aged 16 years or older. ${ }^{17}$ Before the policy experiment, after it was terminated, and in the remaining parts of Sweden, strong beer was only available for purchase at the Swedish state-owned retail monopoly, Systembolaget, with a legal age limit of alcohol purchase set at 21 years. ${ }^{17}$ The alcohol policy experiment was terminated early due to the drastic increase in strong beer consumption, especially among adolescents. ${ }^{17}$ During this time period, medium-strength beer $(3.5 \%-$ $4.5 \%$ alcohol by volume) was nationally available at grocery stores with an age limit of 16 years. ${ }^{16}$

\section{Study population}

The study population was identified by record linkage between the Multi-Generation Register (MGR) and the Population and Housing Censuses (PHC). Both PHC 1965 and 1970 were used to identify individuals' residence information. The study base included all non-adopted individuals born between 1948 and 1953, who were registered in Sweden 1965 and 1970 and and with at least one biological parent identified in the MGR $(n=666639)$. Individuals that were excluded lacked information on residence, lived in a bordering area (the counties of Halland, Älvsborg, Skaraborg, Örebro and Kopparberg) in either 1965 or 1970, moved between the intervention and control area, emigrated from Sweden or died before 1970. The final analytical sample consisted of 528334 individuals; the intervention group consisted of 72110 individuals that were registered in the intervention area both in 1965 and 1970, and the control group consisted of 456224 individuals that were registered in an area unexposed to the alcohol policy experiment (online supplementary figure 1). The study was approved by the Stockholm Regional Ethical Review Board (Ref: 2013/517-31/5).

\section{Outcome measure: alcohol-related morbidity and alcohol-related morality}

Diagnosis of alcohol-related health problems, according to the Swedish version of the International Statistical Classification of Disease versions 8 (1969-1986), 9 (1987-1996) and 10 (from 1997), was obtained from the Hospital Discharge Register and the Cause of Death Register. The outcome was defined through the Swedish index of alcohol-related inpatient care and alcohol-related mortality. ${ }^{24} 25$ These indexes include diagnosis of alcoholic psychoses, alcohol dependency, alcoholic liver disease and the toxic effect of alcohol (table 1). For the outcome of alcohol-related morbidity, first-time hospital admission for an alcohol-related diagnosis was of interest, either as a principal or contributory discharge diagnosis. For the outcome of
Table 1 Swedish index of alcohol-related inpatient care and alcoholrelated mortality according to International Statistical Classification of Disease (ICD) versions 8,9 and 10

\begin{tabular}{ll}
\hline ICD 8 (1969-1986) and ICD & ICD 10 \\
9 (1987-1996) & (from 1997) \\
\hline
\end{tabular}

\begin{tabular}{|llll|}
\hline 291 & Alcoholic psychoses & E24.4 & $\begin{array}{l}\text { Alcohol induced pseudo- } \\
\text { Cushing's syndrome }\end{array}$ \\
\hline 303 & $\begin{array}{l}\text { Alcoholic dependence } \\
\text { syndrome }\end{array}$ & F10 & $\begin{array}{l}\text { Mental and behavioural } \\
\text { disorders due to alcohol } \\
\text { abuse }\end{array}$ \\
\hline $305.0^{*}$ & $\begin{array}{l}\text { Nondependent alcohol } \\
\text { abuse }\end{array}$ & G31.2 & $\begin{array}{l}\text { Degeneration of nervous } \\
\text { system due to alcohol }\end{array}$ \\
\hline $357.5^{*}$ & Alcoholic polyneuropathy & G62.1 & Alcoholic polyneuropathy \\
\hline $425.5^{*}$ & Alcoholic cardiomyopathy & G72.1 & Alcoholic myopathy \\
\hline $535.3^{*}$ & Alcoholic gastritis & 142.6 & Alcoholic cardiomyopathy \\
\hline 571 & Alcoholic liver disease & K29.2 & Alcoholic gastric \\
\hline E860 or & Alcohol poisoning & K70.0 & Alcoholic liver disease \\
\hline
\end{tabular}

E980 and 980

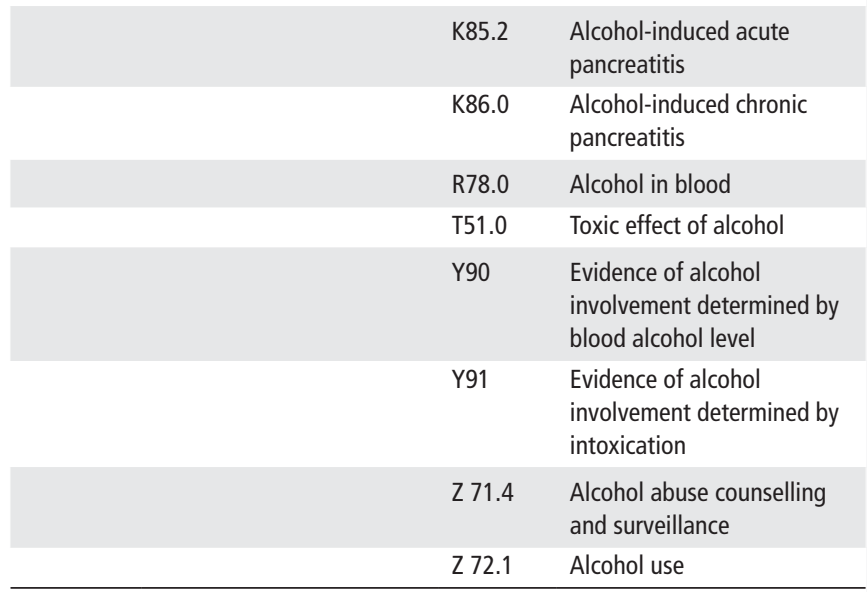

*Only available in ICD 9.

alcohol-related mortality, an alcohol-related diagnosis could be the underlying or contributing cause of death.

\section{Covariates}

From the PHC 1970 and the MGR, several individual and family level covariates were extracted including sex, country of birth, year of birth, maternal age at birth (if missing paternal age was used), highest level of parents education and socioeconomic index (SEI) and registered alcohol-related health problems from both parents. Evidence from previous research has shown these variables to be associated with alcohol-related health problems in different ways. ${ }^{7}$ 26-28 Children born to older mothers are more likely to drink alcohol regularly ${ }^{26}$ and poor childhood SES is associated with poorer adult health. ${ }^{27}$ We also took parents' alcohol-related health problems into account, since parents' drinking habits can influence their child's drinking behaviour. ${ }^{28}$

A regional measure of population density of locality extracted from the PHC 1970 was included. Statistics Sweden defines a locality as a urban area where houses are no more than $200 \mathrm{~m}$ apart and with at least 200 inhabitants regardless of municipal or regional boundaries. ${ }^{29}$ In 1970 , there was a total of 1775 localities in Sweden. ${ }^{30}$ Areas with high population density have higher alcohol availability in terms of number of restaurants and liquor stores compared with areas with lower population density. ${ }^{31-34}$ All covariates were categorised as indicated in table 2. 
Table 2 Descriptive statistics of the intervention and control group $(n=528334)$

\begin{tabular}{|c|c|c|c|}
\hline Characteristics & $\begin{array}{l}\text { Intervention } \\
\text { group }(\mathrm{n}=72110) \\
(\mathrm{n}(\%))\end{array}$ & $\begin{array}{l}\text { Control group } \\
(n=456224)(n \\
(\%))\end{array}$ & $\mathrm{p}$ Value \\
\hline \multicolumn{4}{|l|}{ Sex } \\
\hline Males & $37612(52.2)$ & $234187(51.3)$ & $<0.001$ \\
\hline Females & $34498(47.8)$ & $222037(48.7)$ & \\
\hline Age* $^{*}$ & $17.0 \pm 1.7$ & $17.0 \pm 1.7$ & \\
\hline \multicolumn{4}{|l|}{ Country of birth } \\
\hline Sweden & $70722(98.1)$ & $446771(97.9)$ & 0.010 \\
\hline Outside of Sweden & $1388(1.9)$ & $9453(2.1)$ & \\
\hline \multicolumn{4}{|l|}{ Maternal age at birth } \\
\hline$<20$ & $4975(6.9)$ & $32238(7.1)$ & $<0.001$ \\
\hline $20-24$ & $17680(24.5)$ & $114519(25.1)$ & \\
\hline $25-29$ & $21568(29.9)$ & $135129(29.6)$ & \\
\hline $30-34$ & $15880(22.0)$ & $97429(21.4)$ & \\
\hline $35-39$ & $9216(12.8)$ & $57640(12.6)$ & \\
\hline$>40$ & $2791(3.9)$ & $19269(4.2)$ & \\
\hline \multicolumn{4}{|l|}{ Parental educational levelt‡ } \\
\hline Primary & $43663(60.6)$ & $274858(60.3)$ & $<0.001$ \\
\hline Secondary & $18836(26.1)$ & $114573(25.1)$ & \\
\hline University and above & $5171(7.2)$ & $36054(7.9)$ & \\
\hline Missing & $4440(6.2)$ & $30739(6.7)$ & \\
\hline \multicolumn{4}{|l|}{ Parental SEI† ¥ } \\
\hline High non-manual & $4200(5.8)$ & $28097(6.2)$ & $<0.001$ \\
\hline Middle non-manual & $12052(16.7)$ & $79232(17.4)$ & \\
\hline Low non-manual & $11774(16.3)$ & $69464(15.2)$ & \\
\hline Self-employed/farmer & $5133(7.1)$ & $40915(9.0)$ & \\
\hline Skilled workers & $20731(28.8)$ & $125252(27.5)$ & \\
\hline Unskilled workers & $12823(17.8)$ & $76320(16.7)$ & \\
\hline Others, not classified & $5116(7.1)$ & $34942(7.7)$ & \\
\hline Missing & $281(0.4)$ & $2002(0.4)$ & \\
\hline $\begin{array}{l}\text { Parents alcohol-related health } \\
\text { problems }\end{array}$ & $5596(7.8)$ & $29800(6.5)$ & $<0.001$ \\
\hline Population density of locality†§ & & & $<0.001$ \\
\hline$\geq 99999$ inhabitants & $34538(47.9)$ & $96606(21.2)$ & \\
\hline 50 000-99 999 inhabitants & $4210(5.8)$ & $68049(14.9)$ & \\
\hline 20 000-49 999 inhabitants & $4674(6.5)$ & $59467(13.0)$ & \\
\hline 10 000-19999 inhabitants & $3476(4.8)$ & $48801(10.7)$ & \\
\hline 5000-9999 inhabitants & $4509(6.3)$ & $23374(5.1)$ & \\
\hline 2000-4999 inhabitants & $5170(7.2)$ & $35130(7.7)$ & \\
\hline 1000-1999 inhabitants & $1662(2.3)$ & $18459(4.1)$ & \\
\hline 500-999 inhabitants & $1707(2.4)$ & $13752(3.0)$ & \\
\hline 200-499 inhabitants & $1239(1.7)$ & $12205(2.7)$ & \\
\hline Area not defined as a locality & $10925(15.2)$ & 80381 (17.6) & \\
\hline \multicolumn{4}{|l|}{ Outcome, incidence of } \\
\hline $\begin{array}{l}\text { Alcohol-related morbidity } \\
\text { (1973-2013) }\end{array}$ & $3977(5.5)$ & $23322(5.1)$ & \\
\hline $\begin{array}{l}\text { Alcohol-related mortality } \\
(1971-2013)\end{array}$ & $827(1.1)$ & $4582(1.0)$ & \\
\hline
\end{tabular}

* Mean age (with SD) when the policy change was initiated (1 November 1967).

†Population and Housing Censuses. ${ }^{30}$

$\ddagger$ Paternal or maternal, whichever highest.

$\S A$ locality is defined by Statistics Sweden as an a urban area where houses are no more than $200 \mathrm{~m}$ apart and with at least 200 inhabitants regardless of municipal or regional boundaries.

SEl, socioeconomic index.

\section{Statistical analysis}

Pearson's $\chi^{2}$ test was used for comparisons of baseline characteristics. Separate analysis was conducted for alcohol-related morbidity and mortality. The association of increased alcohol availability and alcohol-related health problems were investigated with Cox proportional hazard regression analyses. The proportional hazard assumption was verified using plot of Schoenfeld residuals. For the outcome of alcohol-related morbidity, persontime was calculated from 1 January 1973, until date of receiving an inpatient alcohol-related diagnosis, date of emigration, date of death or until 31 December 2013, whichever came first. The main reason for not starting the follow-up in 1971 is because the inpatient care register has higher coverage in $1973 .{ }^{35}$ For the outcome of alcohol-related mortality, person-time was calculated from 1 January 1971, until death from an alcohol-related diagnosis, date of death due to another diagnosis, date of emigration or until 31 December 2013, whichever came first. In the regression analysis we first included all individual and family factors as potential confounders. Then to estimate unique baseline hazard for each category of population density of locality, we used a stratified cox regression model. Online supplementary table 1 shows the association between population density of locality and alcohol-related morbidity and mortality within the intervention and control group.

Analyses regarding interaction with sex, age group (14-15, 16-17 and 18-20 years) and childhood SES, defined as parents highest level of education, were performed using Wald test, by introducing the corresponding interaction terms into the adjusted models. Missing values were coded as separate categories. All analyses were computed using Stata Statistical Software V.13.

\section{RESULTS}

Table 2 shows the descriptive statistics of the intervention and control group. All analyses were combined for males and females as no interaction of sex and increased alcohol availability with regard to the outcome of alcohol-related morbidity $(p=0.504)$ or alcohol-related mortality $(p=0.211)$ was found. The intervention and control groups had similar baseline characteristics, with the exception of parents' alcohol-related health problems, which was higher in the intervention group. On a regional level, the intervention area comprised to a larger extent areas with high population density compared with the control area.

During follow-up, a total of 27299 individuals received inpatient care due to an alcohol-related diagnosis and a total of 5409 alcohol-related deaths were registered (table 2). The average follow-up was 38 years for alcohol-related morbidity and 41 years for alcohol-related mortality.

\section{Alcohol-related morbidity}

Compared with the control group, the adolescence exposed to increased alcohol availability had an increased risk of receiving inpatient care for an alcohol-related diagnosis in the crude analysis (HR: $1.09,95 \%$ CI 1.05 to 1.13 , table 3). After including several individual and family level covariates into the model, the increased risk remained, only slightly attenuated. This ratio reduced further in the fully adjusted model (HR: $0.98,95 \% \mathrm{CI}$ 0.95 to 1.02 ).

No evidence of an interaction of age group with increased alcohol availability with regard to alcohol-related morbidity was found $(p=0.363)$. There was an interaction of increased alcohol availability with childhood SES in relation to alcohol-related morbidity $(\mathrm{p}=0.019)$. As seen in table 4 , an inverse association was found among adolescents exposed to the policy change with 
Table 3 Crude and adjusted HRs with $95 \%$ Cls for the associations between increased alcohol availability during adolescence and inpatient care and cause of death due to alcohol-related health problems

\begin{tabular}{lllll}
\hline & Event $\boldsymbol{n}(\%)$ & $\begin{array}{l}\text { Crude } \\
\text { HR }(95 \% \mathrm{Cl})\end{array}$ & $\begin{array}{l}\text { Model 1 HR } \\
\text { adjusted } \\
(95 \% \mathrm{Cl})\end{array}$ & $\begin{array}{l}\text { Model 2 HR } \\
\text { adjusted } \\
(95 \% \mathrm{Cl})\end{array}$ \\
\hline $\begin{array}{l}\text { Alcohol- } \\
\text { related } \\
\text { morbidity }\end{array}$ & $27299(5.1)$ & $1.09(1.05$ to 1.13) & $\begin{array}{l}1.06(1.02 \text { to } \\
1.09)\end{array}$ & $\begin{array}{l}0.98(0.95 \text { to } \\
1.02)\end{array}$ \\
$\begin{array}{l}\text { Alcohol- } \\
\text { related } \\
\text { mortality }\end{array}$ & $5409(1.0)$ & $1.15(1.07$ to 1.24) & $1.12(1.04)$ & $1.02(0.95$ to \\
\hline
\end{tabular}

Crude analysis: unadjusted model.

Model 1: adjusted for sex, year of birth, country of birth (two groups), maternal age (six groups), highest level of parents education (three levels) and SEI (seven groups) and any of the parent's registered inpatient care and cause of death due to alcohol-related health problems.

Model 2: additionally stratified for population density of locality (10 groups).

SEl, socioeconomic index.

parents who had a university degree (HR: 0.79 , 95\% CI 0.66 to 0.95$)$. No clear evidence of an association between increased alcohol availability during adolescence and alcohol-related morbidity among individuals with parents with primary (HR: $1.00,95 \%$ CI 0.96 to $1.05, \mathrm{p}=0.956$ ) or secondary (HR: 1.01 , $95 \%$ CI 0.94 to $1.08, \mathrm{p}=0.773$ ) level of education was found.

\section{Alcohol-related mortality}

The HR for alcohol-related morality was 1.15 (95\% CI 1.07 to 1.24) for individuals exposed to increased alcohol availability during adolescence in the crude analysis, compared with individuals not exposed (table 3 ). In the fully adjusted model, this risk ratio decreased to 1.02 (95\% CI 0.95 to 1.10$)$.

No evidence of an interaction of age group $(p=0.595)$ or childhood SES $(p=0.477)$ with increased alcohol availability with regard to alcohol-related mortality was found.

\section{DISCUSSION}

The present study examined the long-term consequences of lowering the legal age limit for alcohol purchases in Sweden from 21 years to 16 years for 8.5 months, using the alcohol policy experiment that took place during the late 1960s. In the crude analysis, adolescents exposed to the increased alcohol availability appeared to be at increased risk of alcohol-related morbidity and mortality later in life compared with same aged individuals not exposed. However, this increased risk vanished when all covariates were included in the model.

In contrast to some previous research, we did not find that being exposed to a lower legal age for alcohol purchases during adolescence was associated with long-term health consequences, ${ }^{6-9}$ which could be due to several factors. The main aim of the alcohol policy change was to decrease the high strong spirit consumption in Sweden by making a weaker alcohol options more readily available. However, by reducing the legal age limit from 21 years to 16 years, there was a marked increased access to stronger alcohol for the individuals not allowed to purchase alcohol at 'Systembolaget'. During the policy change, there was only a small reduction in wine and strong spirit sales in the intervention area, suggesting that young and old responded differently to the increased alcohol availability. ${ }^{17}$ This is supported by the several reports from local authorities in the intervention area that interpreted the negative development in adolescents' alcohol consumption as a result of the alcohol policy change. ${ }^{17}$ Since the policy experiment terminated early, the exposure period to increased alcohol availability lasted only 8.5 months, which might not have been long enough to have an effect on the outcomes under study. Also, given that medium-strength beer was available for purchases in regular grocery stores from 1965 with an age limit of 16 years. there was a relatively small difference in the strength of the alcohol available for adolescents in the intervention and control area. ${ }^{16}$ This is a limitation of the study design as it could have weakened the potential effect of the strong beer exposure. However, results from previous research using the same alcohol policy change suggest an increased risk of disability pensions among adolescents exposed to the strong beer alcohol policy change. ${ }^{9}$ The underlying mechanisms of the relationship between adolescent alcohol consumption and later alcohol-related problems is not fully understood, and since we do not have individual level data on alcohol consumption, it is difficult to speculate about potential reasons for the differences in findings. 1013

Alcohol-related morbidity and mortality is less common in Sweden compared with USA. ${ }^{36}{ }^{37}$ Consequently, the impact of the policy change had to be very strong in order to see an effect in the outcomes. ${ }^{36}$ Previous research from Sweden measuring self-reported alcohol consumption later in life found only a slight difference between adolescents exposed to a lenient as opposed to strict alcohol policy. ${ }^{18}$ Furthermore, the alcohol index used in the present study only captures a small proportion of the diseases and injuries attributable to alcohol. ${ }^{38}$ Plunk and colleagues found an association between a lowered legal drinking age and increased risk of death due to alcoholic liver disease, liver disease not specified as alcohol related, and cancer of the lip, oral and pharynx. ${ }^{7}$ The alcohol index was used to define the outcome as all diagnoses included require the individual to consume alcohol. Including a wider range of alcohol-related health problems in the outcomes could increase the risk of finding differences between the groups due to factors unrelated to the policy change.

Also, the initial elevated risk found in the crude analysis diminished when a measure of population density was included in the

Table 4 Crude and adjusted HRs with 95\% Cls for the associations between increased alcohol availability during adolescence and inpatient care due to alcohol-related health problems using the Swedish alcohol index, stratified by parents highest level of education

\begin{tabular}{|c|c|c|c|c|c|}
\hline Parents education & $\mathrm{n}$ & Crude HR $(95 \% \mathrm{CI})$ & $\begin{array}{l}\text { Model } 1 \mathrm{HR} \text { adjusted } \\
(95 \% \mathrm{Cl})\end{array}$ & $\begin{array}{l}\text { Model } 2 \mathrm{HR} \text { adjusted } \\
(95 \% \mathrm{Cl})\end{array}$ & Event $\boldsymbol{n}(\%)$ \\
\hline Primary & 318130 & 1.12 (1.08 to 1.17$)$ & 1.09 (1.04 to 1.14$)$ & $1.00(0.96$ to 1.05$)$ & $17522(5.5)$ \\
\hline Secondary & 133287 & 1.08 (1.01 to 1.16$)$ & 1.06 (0.99 to 1.14$)$ & 1.01 (0.94 to 1.08$)$ & $6516(4.9)$ \\
\hline University & 41188 & 0.81 (0.68 to 0.97$)$ & 0.82 (0.69 to 0.98$)$ & 0.79 (0.66 to 0.95$)$ & $1278(3.1)$ \\
\hline
\end{tabular}

Crude analysis: unadjusted model.

Model 1: adjusted for sex, year of birth, country of birth (two groups), maternal age (six groups), highest level of parents SEI (seven groups) and any of the parent's registered inpatient care and cause of death due to alcohol-related health problems.

Model 2: additionally stratified for population density of locality (10 groups). 
model, which has not been included in previous research. ${ }^{6-8}$ This appears to be an important covariate when studying the relationship between increased alcohol availability and alcohol-related health problems, since areas with a high population density tend to have a greater alcohol availability (ie, more restaurants and liquor stores) compared with areas with lower population density, which in turn can lead to higher alcohol consumption and alcohol-related harm. ${ }^{34}$ In the current study, a higher proportion of individuals lived in an area with high population density in the intervention area (47.9\%) compared with the control group (21.2\%). During the alcohol policy experiment, a clear connection was found between population density and strong beer sales, the highest being in Gothenburg. ${ }^{17}$ Our results suggest that there could be other factors driving the initial differences between the groups unrelated to the policy change. It is difficult to hypothesise the potential influence such a regional level might have on similar research previously published, ${ }^{6-8}$ since the positive association between increased alcohol availability and disability pension remained in our previous study using the same policy change, even after adjusting for population density of locality. ${ }^{9}$

In line with previous research, high SES appears to be a protective factor in relation to alcohol-related health problems. A considerable body of research has documented a social gradient in relation to alcohol-related morbidity and mortality. ${ }^{20}{ }^{21}$ Thus, these results are likely to be a result of the existing social gradient but could also reflect socioeconomic differences in response to the alcohol policy change.

\section{Strengths and limitations}

Using a natural experiment setting of an alcohol policy change, a large sample size and long follow-up are major strengths. It is difficult to establish a causal link between alcohol consumption during adolescence and long-term alcohol-related health problems due to the inability to control for all relevant confounders and the risk of social desirability bias in self-reported data on alcohol consumption. ${ }^{10} 39$ These sources of bias should be less relevant in the present study since the increased access to alcohol among adolescents was exogenously induced. ${ }^{2}$ However, the lack of individual level data on alcohol consumption leaves unanswered questions on the role of adolescent drinking patterns in relation to alcohol-related morbidity and mortality that might be more important than the age at drinking onset. ${ }^{8}$

The obtained results were based on register-derived data that decrease the risk of self-report bias and attrition. This also enabled us to obtain residence information during the experimental period with great accuracy, thus decreasing the risk of misclassification of exposure.

The outcomes were obtained from high-quality and reliable sources using the index of alcohol-related health problems. ${ }^{24} 25$ Although the outcome is well defined, it only captures the severe cases and a small proportion of the health problems attributable to alcohol. ${ }^{38}$ Perhaps we would have found an effect of the policy change if we were able to use a wider range of alcohol-related health problem as the outcome measure. However, as previously mentioned, since we do not have individual-level data on alcohol consumption, it would be impossible to disentangle whether any effect found would be due to the increased alcohol availability or some other factor.

\section{CONCLUSION}

Our long-term follow-up of a natural experiment in Sweden, when strong beer was made temporally available in grocery stores, did not show an increased risk of alcohol-related morbidity and mortality later in life among adolescents exposed to this policy change when taking population density of locality into account.

\section{What is already known on this subject}

- Alcohol consumption at a young age is a strong indicator of later alcohol-related health problems.

- Enforcing a high legal age limit for alcohol purchases decreases alcohol availability to adolescents which, in the short term, leads to decrease in adolescent drinking and acute alcohol-related harm.

\section{What this study adds}

- Using data from a natural experiment setting of an alcohol policy change with a long-term follow-up, we did not find any evidence of any long-term increased risks of alcoholrelated morbidity and mortality among individuals exposed to an increased alcohol availability during adolescence. The initial elevated risk among the exposed adolescents vanished after including a measure of population density in the models, which is important to consider in future research.

Contributors FR conceived the study in collaboration with TN, MR and GDS. FR and JdM worked with the acquisition of the data. TJ performed the initial analyses in collaboration with FR, JdM and ET. MW drafted the initial version of the manuscript. PT and ET revised the initial analyses, and ET revised the manuscript critically for important intellectual content. All authors provided substantial editing to the final manuscript.

Funding This work was supported by grants to FR from the Swedish Research Council for Health, Working Life and Welfare (FORTE) number 2012-0989 and from Karolinska Institute's funding for PhD students (KID) number 2012-126 (no 3-847/2013). GDS's work was supported by the Medical Research Council Integrative Epidemiology Unit at the University of Bristol (MC_UU_12013/1, MC_UU_12013/9).

Competing interests None declared.

Ethics approval Stockholm Regional Ethical Review Board.

Provenance and peer review Not commissioned; externally peer reviewed.

(c) Article author(s) (or their employer(s) unless otherwise stated in the text of the article) 2017. All rights reserved. No commercial use is permitted unless otherwise expressly granted.

\section{REFERENCES}

1 WHO. Alcohol in the European Union: consumption, harm and policy approaches. Copenhagen: The WHO Regional Office Europe, 2012.

2 Craig P, Cooper C, Gunnell D, et al. Using natural experiments to evaluate population health interventions: new medical research council guidance. J Epidemiol Community Health 2012;66:1182-6.

3 Nelson JP, McNall AD. Alcohol prices, taxes, and alcohol-related harms: A critical review of natural experiments in alcohol policy for nine countries. Health Policy 2016;120:264-72.

4 Anderson P, Chisholm D, Fuhr DC. Effectiveness and cost-effectiveness of policies and programmes to reduce the harm caused by alcohol. Lancet 2009;373:2234-46.

5 Wagenaar AC, Toomey TL. Effects of minimum drinking age laws: review and analyses of the literature from 1960 to 2000. J Stud Alcohol Supp/ 2002;14:206-25.

6 Plunk AD, Cavazaos-Rehg P, Bierut LJ, et al. The persistent effects of minimum legal drinking age laws on drinking patterns later in life. Alcohol Clin Exp Res 2013:37:463-9.

7 Plunk AD, Krauss MJ, Syed-Mohammed $H$, et al. The Impact of the minimum legal drinking age on alcohol-related chronic disease mortality. Alcohol Clin Exp Res 2016;40:1761-8

8 Norberg KE, Bierut LJ, Grucza RA. Long-term effects of minimum drinking age laws on past-year alcohol and drug use disorders. Alcohol Clin Exp Res 2009;33:2180-90.

9 Thern E, de Munter J, Hemmingsson T, et al. Effects of increased alcohol availability during adolescence on the risk of all-cause and cause-specific disability pension: a natural experiment. Addiction 2017;112:1004-12.

10 McCambridge J, McAlaney J, Rowe R. Adult consequences of late adolescent alcoho consumption: a systematic review of cohort studies. PLoS Med 2011:8:e1000413. 
11 Norström T, Pape H. Associations between adolescent heavy drinking and problem drinking in early adulthood: implications for prevention. J Stud Alcohol Drugs 2012;73:542-8.

12 Marshall EJ. Adolescent alcohol use: risks and consequences. Alcohol Alcohol 2014; $49: 160-4$

13 Maimaris W, McCambridge J. Age of first drinking and adult alcohol problems: systematic review of prospective cohort studies. J Epidemiol Community Health 2014:68:268-74.

14 DeWit DJ, Adlaf EM, Offord DR, et al. Age at first alcohol use: a risk factor for the development of alcohol disorders. Am J Psychiatry 2000;157:745-50.

15 Norström T, Ramstedt M. Sweden--is alcohol becoming an ordinary commodity? Addiction 2006;101:1543-5.

16 Noval S, Nilsson T. The effects of medium beer on consumption levels and the rise in overall alcohol consumption (In Swedish: Mellanölets effekt på konsumtionsnivån och tillväxten hos den totala alkoholkonsumtionen). Linköping, Sweden: Samhällsvetenskapliga institutionen, Universitetet i Linköping, 1984.

17 SOU. The pilot project of strong beers sales in gothenburg and bohus County and värmland country (In Swedish: Försöksverksamheten med fri starkölsförsäljning i göteborgs och bohus samt värmlands län. l: svenska folkets alkoholvanor). Rapport från försök och utredningar $i$ alkoholpolitiska utredningens regi. Stockholm: Finansdepartmentet, 1971.

18 Raninen J, Härkönen J, Landberg J. Long-term effects of changes in Swedish alcohol policy: can alcohol policies effective during adolescence impact consumption during adulthood? Addiction 2016;111:1021-6.

19 Nilsson JP. Alcohol availability, prenatal conditions, and long-term economic outcomes. Journal of Political Economy 2017;125:1149-207.

20 Probst C, Roerecke M, Behrendt S, et al. Socioeconomic differences in alcoholattributable mortality compared with all-cause mortality: a systematic review and meta-analysis. Int J Epidemiol 2014;43:1314-27.

21 Mäkelä P, Paljärvi T. Do consequences of a given pattern of drinking vary by socioeconomic status? A mortality and hospitalisation follow-up for alcohol-related causes of the finnish drinking habits surveys. J Epidemiol Community Health 2008;62:728-33.

22 Schmidt LA, Mäkelä P, Rehm J, et al. Equity, social determinants and public health programmes. Alcohol: equity and social determinants. 11. Geneva: Switzerland World Health Organization, 2010.

23 Herttua K, Mäkelä P, Martikainen P. Changes in alcohol-related mortality and its socioeconomic differences after a large reduction in alcohol prices: a natural experiment based on register data. Am J Epidemiol 2008;168:1110-8.
24 Socialstyrelsen. Cause of death 2013 (In Swedish: Dödsorsaker 2013). Stockholm, Sweden: Sveriges officiella statistik, 2014.

25 Socialstyrelsen. In-patient care diagnoses (In Swedish: Sjukdomar i sluten vård 19872001). Stockholm: Socialstyrelsen Epidemiologiskt centrum, 2003.

26 Barclay K, Myrskylä M. Maternal age and offspring health and health behaviours in late adolescence in Sweden. SSM Popul Health 2016;2:68-76.

27 Rahkonen O, Lahelma E, Huuhka M. Past or present? Childhood living conditions and current socioeconomic status as determinants of adult health. Soc Sci Med 1997:44:327-36

28 Rossow I, Felix L, Keating P, et al. Parental drinking and adverse outcomes in children: A scoping review of cohort studies. Drug Alcohol Rev 2016;35:397-405.

29 Statistics Sweden. Localities 2010: population, age and gender (In Swedish with English summary). Stockholm, Sweden, 2012.

30 Statistics Sweden. Population and housing census 1970. Part 2, Population in localities (In Swedish: folk- och bostadsräkningen 1970. Del 2, befolkning i tätorter). Stockholm, 1972

31 Rossow I, Norström T. The use of epidemiology in alcohol research. Addiction 2013;108:20-5.

32 Gruenewald PJ. Regulating availability: how access to alcohol affects drinking and problems in youth and adults. Alcohol Res Health 2011;34:248-56.

33 Babor T. Alcohol: no ordinary commodity: research and public policy. Oxford: Oxford University Press, 2010.

34 Centralförbundet för alkohol- och narkotikaupplysning. Drug trends in Sweden 2014 (In Swedish: Drogutvecklingen i Sverige 2014). Stockholm, Sweden, 2014. Report No: CAN rapport 144

35 Socialstyrelsen. Quality and content in the National Patient Register (In Swedish: Kvalitet och innehåll i patientregistret). Stockholm: Socialstyrelsen Epidemiologiska centrum, 2009.

36 Statens Folkhälsoinstitut. Public Health in Sweden: 2013 (In Swedish: Folkhälsan i Sverige: årsrapport 2013). Stockholm: Socialstyrelsen, 2013.

37 National Institutet of Alcohol Abuse and Alcoholism. Alcohol facts and statistics. Bethesda, MD, United States, 2016.

38 Rehm J, Baliunas D, Borges GL, et al. The relation between different dimensions of alcohol consumption and burden of disease: an overview. Addiction 2010;105:817-43.

39 Davis CG, Thake J, Vilhena N. Social desirability biases in self-reported alcohol consumption and harms. Addict Behav 2010;35:302-11. 